\title{
Design and fabrication of compositionally graded inorganic oxide thin films: Mechanical, optical and permeation characteristics
}

\author{
Y.-H. Choi ${ }^{\text {a }}$, X. Bulliard ${ }^{\text {a }}$, A. Benayad ${ }^{\text {a }}$, Y. Leterrier ${ }^{\text {b }}$, J.-A.E. Månson ${ }^{\text {b }}$, K.-H. Lee ${ }^{\text {a }}$, \\ D. Choi ${ }^{\mathrm{c}, *}$, J.-J. Park ${ }^{\mathrm{a}, * *}$, J. Kim ${ }^{\mathrm{a}}$ \\ ${ }^{a}$ Samsung Advanced Institute of Technology, Yongin, Gyeonggi 446-712, Republic of Korea \\ ${ }^{\mathrm{b}}$ Laboratoire de Technologie des Composites et Polymères (LTC), Ecole Polytechnique Fédérale de Lausanne (EPFL), Station 12, \\ CH-1015 Lausanne, Switzerland \\ ${ }^{\mathrm{c}}$ Department of Mechanical Engineering, College of Engineering, Kyung Hee University, Yongin, Gyeonggi 446-701, Republic of Korea
}

Received 21 June 2010; accepted 12 August 2010

\begin{abstract}
Different types of inorganic oxide films composed of a chemical composition gradient single layer were designed, fabricated and characterized. Compositionally graded thin films were created by power-controlled co-sputtering of alumina $\left(\mathrm{Al}_{2} \mathrm{O}_{3}\right)$ and silica $\left(\mathrm{SiO}_{2}\right)$ at room temperature, allowing the structural design of the film to be tailored at the nanometer scale. Two distinct graded thin films were fabricated: one with a compositionally asymmetric structure consisting of a $\mathrm{SiO}_{2}$-rich bottom interface and a $\mathrm{Al}_{2} \mathrm{O}_{3}$-rich top surface, and the other with a compositionally balanced sandwich structure consisting of both the top surface and bottom interface rich in $\mathrm{SiO}_{2}$ and a core rich in $\mathrm{Al}_{2} \mathrm{O}_{3}$ (referred to as SGS for 'sandwich graded structure'). Smoothly graded thin films without interfacial boundaries were verified by Auger electron spectroscopy profiles. X-ray photoelectron spectroscopy demonstrated that the $\mathrm{Al}_{2} \mathrm{O}_{3} / \mathrm{SiO}_{2}$ graded structures

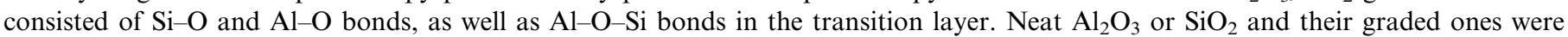
all investigated for their mechanical, optical and permeation properties. A SGS thin film presented the best mechanical stability (i.e., about three times improved film toughness of a neat $\mathrm{Al}_{2} \mathrm{O}_{3}$ single layer), demonstrating that balanced internal stresses and alternating bonding structures, achieved via a graded structure without interfaces, are crucial for enhancing mechanical stability. Furthermore, neat and graded thin films exhibited the similar level of optical transmittance and the permeation properties for the graded films were well matched with the behaviors of mechanical stability.
\end{abstract}

(C) 2010 Acta Materialia Inc. Published by Elsevier Ltd. All rights reserved.

Keywords: Functionally graded materials; Thin films; Interface structure; Sputtering; Toughness

\section{Introduction}

Inorganic oxides are used in a variety of electronic, biological and structural devices owing to their unique properties such as optical transparency, high thermal/mechanical resistivity and high electrical properties, depending on the material [1-3]. Examples are insulators in thin film transis-

\footnotetext{
* Corresponding author. Tel.: +82 31201 3320; fax: +82 312028106. ** Corresponding author. Tel.: +82 31280 6775; fax: +82 312806728.

E-mail addresses: dchoi@khu.ac.kr (D. Choi), jongjin00.park@samsung. com (J.-J. Park).
}

tors [4], optical spacers or electron/hole blocking/transporting layers in photovoltaic systems [5,6], encapsulating gas barriers for organic electronics [7,8] and dielectric material in plasmonic molecular sensors $[9,10]$. Recently, as many devices have been developed with light, thin and even flexible characteristics, the need for thin film types of functional inorganic oxides is rapidly increasing, and the mechanical stability of inorganic thin films is inevitably becoming important for applications, particularly in flexible electronics [11-14].

The intrinsic mechanical strength of inorganic oxides is extremely high, even though they are brittle. However, 
depending on the fabrication process, the extrinsic properties of inorganic oxide thin films are significantly changed by defects such as pinholes or cracks introduced during manufacture. In general, inorganic oxide thin films are fabricated on a substrate by sputtering, chemical vapor deposition (CVD), atomic layer deposition (ALD), laser ablation and sol-gel coating [15-19]. Furthermore, selfsupporting ultrathin films have been developed by several preparative techniques, such as solvent casting, self-assembly ABA triblock copolymer and cross-linking of Langmuir-Blodgett [20-22]. Among these fabrication methods, ALD provides high-density and high-quality (i.e., low defects) thin films based on the layer-by-layer deposition process at atomic scale, but the deposition method is limited by the restricted size and a high-cost, low-throughput and slightly high-temperature fabrication process. However, radio-frequency (RF) magnetron sputtering can provide a cost-effective, high-throughput and relatively low temperature process with large area scalability and co-sputtering capability, but the thin films deposited from vapor usually have many defects, thus severely degrading the physical properties of the films. Since those defects also control the toughness and the related strain to failure of the layer, it is of vital importance to minimize the defects to achieve uniform and macroscopic robust high-quality thin films through a high-throughput process on a large area [2].

Functionally graded materials (FGM) [23-25] offer a way to improve the mechanical resistance of inorganic materials. As an example, Hertzian cracks induced by indentation can be drastically reduced using graded materials [26]. The benefit is due to the increase in elastic modulus with increasing depth from the top surface, reducing the maximum principal tensile stresses in the bulk material of the FGM. A similar approach has recently been used to create films with a composition gradient across the thickness in an organic/inorganic hybrid structure [19]. The main objective was to prevent delamination (i.e., improving the adhesion property) between the film layer and a polymer substrate by creating a smooth transition in mechanical properties and reducing stress discontinuities across the interface. Disadvantages of previous techniques for FGM are, however, the thickness of the final film structure, greater than a few micrometers, and the complex, hightemperature solution-based fabrication processes involved, such as the annealed diffusion method, electrochemical deposition, metal-organic CVD and sol-gel coating.

This work exploits the graded approach in a simpler way, to create high-quality single layer thin films at low temperature. Inorganic oxide thin films with thickness $<200 \mathrm{~nm}$, and composition gradient controlled at the nanometer scale across their thickness, are achieved using RF magnetron co-sputtering of $\mathrm{Al}_{2} \mathrm{O}_{3}$ and $\mathrm{SiO}_{2}$. Differing graded thin films are investigated, with attention paid to their mechanical, optical and permeation properties, and compared with those of non-graded neat single layers. A crucial point is the absence of sharp interfaces across the thickness, with a smooth chemical transition from the two distinct materials, as confirmed by the presence of $\mathrm{Al}-\mathrm{O}-\mathrm{Si}$ bonds in the film. This approach offers great flexibility for thin film design at a nanometer scale, with the capability to choose the composition of materials in contact with the substrate as well as the core composition of the film, so as to provide optimal interfacial control and mechanical integrity.

\section{Experimental}

\subsection{Power-controlled co-sputtering for a graded structure}

A modified RF magnetron co-sputtering machine (INFOVION Inc.) in which the cathode guns are computer-controlled was used to fabricate thin films with a graded structure. Programmed automatic control for the cathode guns was realized in the range $0-600 \mathrm{~W}$ for both $\mathrm{Al}_{2} \mathrm{O}_{3}$ and $\mathrm{SiO}_{2}$ over a time of $10 \mathrm{~min}$. It was arranged that one cathode gun has an $\mathrm{Al}_{2} \mathrm{O}_{3}$ target (99.99\% purity) and the other has a $\mathrm{SiO}_{2}$ target ( $99.99 \%$ purity). Single layered graded structures were then fabricated on flexible polymer substrates such as polyethylene terephthalate (PET) and polyether sulfone (PES), and on a $\mathrm{Si}\left(\begin{array}{lll}1 & 0 & 0\end{array}\right)$ substrate by non-reactive RF magnetron co-sputtering processes at a low temperature $<100{ }^{\circ} \mathrm{C}$ in $\mathrm{Ar}$ at a flow rate of $100 \mathrm{sccm}$. The working pressure was 5 mtorr and the substrate was rotated at $10 \mathrm{rpm}$ during deposition. The reference samples of pure (meaning 99.99\%) $\mathrm{Al}_{2} \mathrm{O}_{3}$ and $\mathrm{SiO}_{2}$ were prepared by non-reactive $\mathrm{RF}$ magnetron co-sputtering with power ratios of 600:0 W (for $\mathrm{Al}_{2} \mathrm{O}_{3}$ ) and 0:600 W (for $\mathrm{SiO}_{2}$ ).

\subsection{Structural characterization}

The microstructures of the films were investigated in cross-section by transmission electron microscopy (TEM; Tecnai f20st FEI). Samples for TEM were prepared by mechanical pre-thinning and Ar ion milling at $4 \mathrm{keV}$. Phase analysis of films was performed by X-ray diffraction (XRD) using $\mathrm{Cu} \mathrm{K}_{\alpha}$ radiation $(\lambda=0.154 \mathrm{~nm})$. The chemical composition of the graded structures was characterized by X-ray photoelectron spectroscopy (XPS; Physical Electronics Quantum 2000 scanning ESCA microprobe) using focused monochromatized $\mathrm{Al} \mathrm{K}_{\alpha}$ radiation $(1486.6 \mathrm{eV}$; the diameter of the irradiated area was $100 \mu \mathrm{m})$. The spectrometer, with energy resolution $0.3 \mathrm{eV}$, was calibrated using photoemission lines of gold $(\mathrm{Au} 4 \mathrm{f} 7 / 2=84.0 \mathrm{eV}$, with reference to Fermi level). Depth-composition profiles of the graded $\mathrm{Al}_{2} \mathrm{O}_{3} / \mathrm{SiO}_{2}$ structure were performed using Auger electron spectroscopy (AES; Microlab 350), with a $10 \mathrm{keV}$ electron-beam and $1 \mathrm{keV} \mathrm{\textrm {Ar } ^ { + }}$ at an angle of incidence of $30^{\circ}$ for depth sputtering into a $1 \times 1 \mathrm{~mm}$ area. Optical transmission spectra of the graded films were obtained using a Varian Cary 5000 UV-Vis spectrometer. The refractive indexes of the homogeneously mixed films were determined by polarizer rotating ellipsometer (ElliSE(UV)-FM9) in the optical range 238-1033 nm. 


\subsection{Fragmentation tests}

Fragmentation tests were undertaken to determine the cohesive and adhesive properties of the thin films on the polymer substrates. The evolution of crack patterns in the brittle coating is monitored in situ as a function of the uniaxial tensile load applied to the substrate, using a microscope. A tensile load was applied to rectangular film specimens $\left(50 \times 5 \mathrm{~mm}^{2}\right)$ with a computer-controlled Minimat unit (Rheometric Systems), using a stepper motor for crosshead displacement to an accuracy of within $1 \mu \mathrm{m}$. The tensile unit was mounted under an optical microscope (Olympus BX60) equipped with a charge-coupled device camera (Soft Imaging Systems ColorView II) for non-contact video extensometry of specimen strain, with accuracy better than $10^{-4}$ in the strain values [27]. This method eliminated problems with frame compliance. Cracking of the coatings was analyzed at increasing strain levels via the crack density $(C D)$, calculated from the mean number of cracks $N_{i}$, counted on $k=7$ micrographs of width $W$, at strain $\varepsilon$, as $C D=(1+\varepsilon) \sum_{i=1}^{k} N_{i} / k W$. The factor $(1+\varepsilon)$ is a correction for crack opening. The crack onset strain (COS), corresponding to the onset of unstable propagation of the first crack, was obtained by extrapolation of the $C D$ data to $C D=0$.

\subsection{Measurement of permeation property}

To investigate the water vapor transmission rate (WVTR) characteristic for the graded structures and the references, thin films were prepared on $100-\mu \mathrm{m}$-thick PET substrates. The WVTR was measured for films with an active area of $50 \mathrm{~cm}^{2}$, at $37.8{ }^{\circ} \mathrm{C}$ and $100 \%$ relative humidity, using a MOCON AQUATRAN ${ }^{\circledR}$ Model 1, with a reliable detectable range of $0.0001-60 \mathrm{~g} \mathrm{~m}^{-2} \mathrm{day}^{-1}$.

\section{Results and discussion}

\subsection{Design of chemical composition graded structures}

RF magnetron co-sputtering equipment was designed, with $\mathrm{SiO}_{2}$ and $\mathrm{Al}_{2} \mathrm{O}_{3}$ targets, in which the power of each cathode gun was regulated independently to control the deposition of inorganic layers with graded mixed composition. The power was matched so as to create a composition gradient, using a succession of stepwise stages of $\sim 10 \mathrm{~min}$, with a power intensity varying between 0 and $600 \mathrm{~W}$ (see Fig. 1a). To verify the progressive change in composition between deposition stages, XPS was conducted on a sample of graded structure with the bottom interface composed entirely of $\mathrm{SiO}_{2}$ and the top surface entirely of $\mathrm{Al}_{2} \mathrm{O}_{3}$. Fig. $1 \mathrm{~b}$ shows XPS survey spectra and highlights the monotonic decrease in the intensity of Si-related peaks ( $\mathrm{Si} 2 \mathrm{~s}$ and $\mathrm{Si} 2 \mathrm{p}$ core peaks) and the increase in Al-related peaks ( $\mathrm{Al} 2 \mathrm{~s}$ and $\mathrm{Al} 2 \mathrm{p}$ core peaks) without significant change in the $\mathrm{O}$ $1 \mathrm{~s}$ peak intensity. This observation confirms that this technique is capable of making single layered inorganic thin

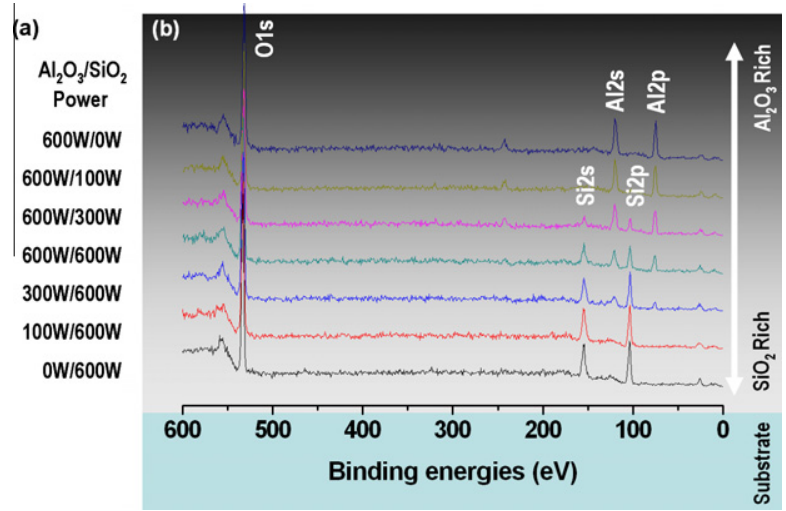

Fig. 1. Design of a chemical composition graded nanoarchitecture by power-controlled co-sputtering. (a) Power ratio of each cathode gun for $\mathrm{Al}_{2} \mathrm{O}_{3}$ and $\mathrm{SiO}_{2}$ targets, respectively. The power ratio for the guns was automatically controlled every $10 \mathrm{~min}$. (b) Typical XPS spectra for Sirelated peaks ( $\mathrm{Si} 2 \mathrm{~s}$ and $\mathrm{Si} 2 \mathrm{p}$ core peaks) and Al-related peaks ( $\mathrm{Al} 2 \mathrm{~s}$ and Al 2 p core peaks).

films with a chemical composition that is smoothly graded. The film with a variety of graded structures is easily realized through modulation of the power ratio of each cathode gun during co-sputtering.

Using this method for graded structures, the authors designed thin films with a graded structure at nanometer scale. Two distinct graded architectures were then designed: one with a continuous composition change from a $\mathrm{SiO}_{2}$-rich bottom interface to an $\mathrm{Al}_{2} \mathrm{O}_{3}$-rich top surface (referred to as AGS for 'asymmetric graded structure'; Fig. 2a) and the other with both the top surface and bottom interface rich in $\mathrm{SiO}_{2}$ and a core rich in $\mathrm{Al}_{2} \mathrm{O}_{3}$ (referred to as SGS; Fig. 2b). In these structures, $\mathrm{SiO}_{2}$ was coated on the polymer substrate in order to reduce internal stresses and improve adhesion, since $\mathrm{Al}_{2} \mathrm{O}_{3}$ has a high tensile modulus but is brittle, and $\mathrm{SiO}_{2}$ is tougher than $\mathrm{Al}_{2} \mathrm{O}_{3}$.

It is important to check that the deposition technique did not induce any further interface within the single layer, while modifying the chemical composition by tuning the power of each cathode. Fig. $2 \mathrm{c}$ and d shows TEM images of the graded structures on a $\mathrm{Si}$ wafer. No interfacial boundaries in the graded structures were visible. The high-resolution TEM (HR-TEM) images (right top and bottom images of each TEM image) at positions I and II of the TEM images clearly confirm the absence of boundaries in the graded structures. Furthermore, all the graded films are of amorphous structure confirmed by the TEM images and the XRD results. (No distinct diffraction peaks were checked; data not shown.) AES was then used to study the concentration depth-profiles of the graded samples. Fig. 2e shows a linear decrease in the Si concentration from the bottom interface to the top surface, whereas Al increases linearly in the continuous graded film. The atomic concentration of oxygen was constant throughout the layer. The profiles are accurately linear without marked steps, confirming the regularity of the change in concentration with thickness. Fig. 2f shows the profile for the SGS. 
(a)

\begin{tabular}{|c|c|}
\hline \multicolumn{2}{|c|}{$\mathbf{A l}_{2} \mathbf{O}_{3}-\mathbf{S i O}_{2}$} \\
\hline $600 W$ & $100 W$ \\
\hline $500 W$ & $200 w$ \\
\hline $400 W$ & $300 w$ \\
\hline $300 W$ & $400 W$ \\
\hline $200 W$ & $500 W$ \\
\hline $100 W$ & $600 \mathrm{~W}$ \\
\hline & ubstra \\
\hline
\end{tabular}

(b)

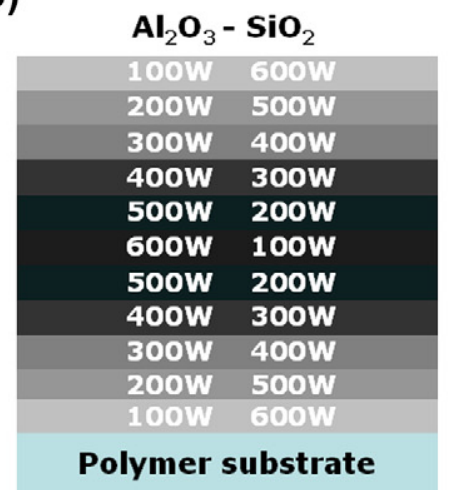

(c)

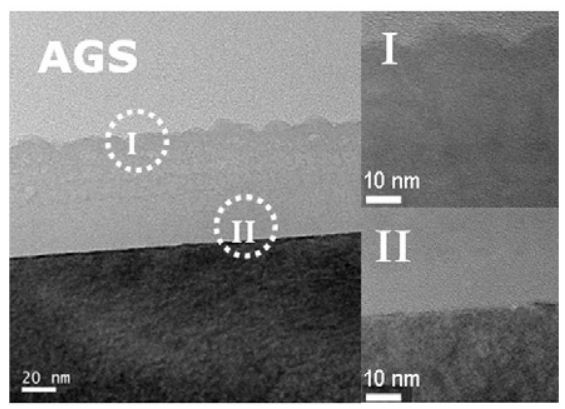

(d)

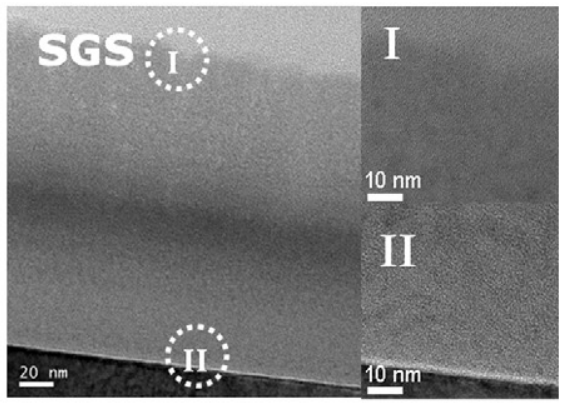

(e)

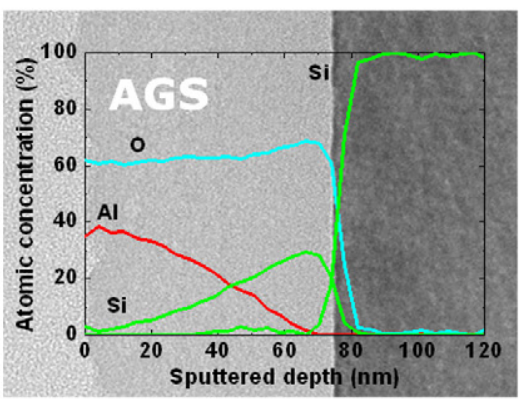

(f)

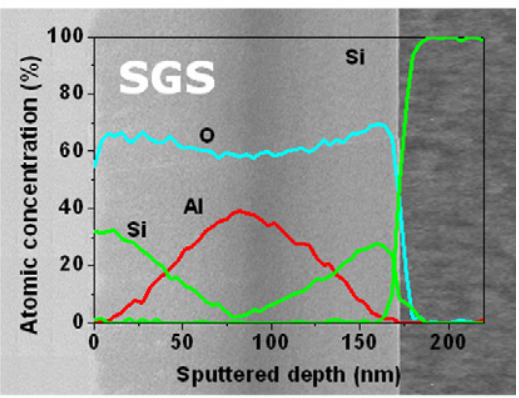

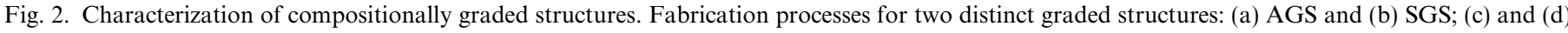

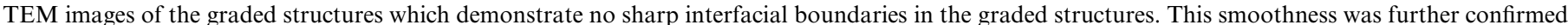

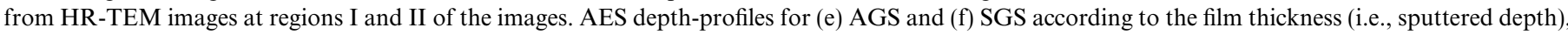
showing the continuously graded concentration of each inorganic material.

Again the profiles were smooth, with regular convex or concave curvatures for $\mathrm{Si}$ and $\mathrm{Al}$, respectively.

\subsection{Characterization of bond type}

The results obtained by TEM and AES show that the single graded layers have no abrupt interfaces, with a smooth change in concentration. XPS was then used to analyze the nature of chemical bonding in the samples, in particular the possibility of inter-mixing. The XPS studies focused on the core peaks of simple mixtures (i.e., nongraded) of $\mathrm{Al}_{2} \mathrm{O}_{3} / \mathrm{SiO}_{2}$ prepared by changing the power ratio applied to the $\mathrm{Al}_{2} \mathrm{O}_{3}$ and $\mathrm{SiO}_{2}$ targets. Two pure $\mathrm{Al}_{2} \mathrm{O}_{3}$ and $\mathrm{SiO}_{2}$ films were also prepared and used as references. Analysis of core peak binding energies in association with their chemical shifts allowed us to determine the local chemical environments of $\mathrm{Al}$ and Si elements.

Fig. 3 shows high-resolution XPS Al 2p, Si $2 p$ and O 1s core-level spectra of $\mathrm{Al}_{2} \mathrm{O}_{3} / \mathrm{SiO}_{2}$ mixture films for differing values of the co-sputtering power ratio. The XPS Si $2 p$ and Al 2p core-level spectra corresponding to the pure $\mathrm{SiO}_{2}$ and $\mathrm{Al}_{2} \mathrm{O}_{3}$ thin films are at 103.6 and $74.6 \mathrm{eV}$ (see Table 1 and Fig. 3), associated with +4 and +3 formal degrees for $\mathrm{Si}$ and $\mathrm{Al}$, and corresponding to $\mathrm{Si}-\mathrm{O}$ and $\mathrm{Al}-\mathrm{O}$ bonds, respectively. The $\mathrm{O} 1 \mathrm{~s}$ core peaks of the $\mathrm{SiO}_{2}$ and $\mathrm{Al}_{2} \mathrm{O}_{3}$ films were observed at 532.7 and $531.2 \mathrm{eV}$, corresponding to $\mathrm{O}^{2-}$ ions in the $\mathrm{Si}-\mathrm{O}$ and $\mathrm{Al}-\mathrm{O}$ local environment, respectively. The XPS $\mathrm{Al} 2 \mathrm{p}$ and $\mathrm{Si} 2 \mathrm{p}$ core level peaks for the $\mathrm{Al}_{2} \mathrm{O}_{3} / \mathrm{SiO}_{2}$ mixture layer, deposited at the power ratio $300: 600 \mathrm{~W}$, are positioned at 76.1 and $103.6 \mathrm{eV}$, respectively, and are attributed to the presence of suboxide $\mathrm{AlO}_{x}$ in the strongly covalent $\mathrm{SiO}_{2}$ network. This result indicates that $\mathrm{Si}-\mathrm{O}-\mathrm{Al}$ bonds are incorporated in the $\mathrm{Si}-$ $\mathrm{O}$ network. The Al 2p chemical shift toward lower binding energy (75.6 eV) was more pronounced for the $\mathrm{Al}_{2} \mathrm{O}_{3} / \mathrm{SiO}_{2}$ layers deposited at 600:300 W, implying a change in film composition with increasing $\mathrm{Al}_{2} \mathrm{O}_{3}$ content, from the $\mathrm{Si}-$ $\mathrm{O}$ bond type to the $\mathrm{Si}-\mathrm{O}-\mathrm{Al}$ bond type. Further addition of $\mathrm{Al}_{2} \mathrm{O}_{3}\left(600: 100 \mathrm{~W}\right.$ for $\left.\mathrm{Al}_{2} \mathrm{O}_{3} / \mathrm{SiO}_{2}\right)$ caused the $\mathrm{Al} 2 \mathrm{p}$, Si $2 \mathrm{p}$, and $\mathrm{O} 1 \mathrm{~s}$ core peaks to shift to lower binding energies, indicating a change from $\mathrm{Si}-\mathrm{O}-\mathrm{Al}$ bond type to the predominant $\mathrm{Al}-\mathrm{O}$ bond in $\mathrm{Al}_{2} \mathrm{O}_{3}$.

Also, a clear change in the full width at half maximum (FWHM) was observed when the power ratio was $\sim 1: 1$ (i.e., $\sim 600: 600 \mathrm{~W}$ ). This change indicates the presence of a disordered system and/or the existence of distinct local environments for $\mathrm{Al}, \mathrm{Si}$ and $\mathrm{O}$ atoms (i.e., $\mathrm{Si}-\mathrm{O}, \mathrm{Al}-\mathrm{O}$ and $\mathrm{Al}-\mathrm{O}-\mathrm{Si}$ bonds). These results show that a continuous change in the local chemical bond type occurs as the applied power ratio is changed. 
(a)

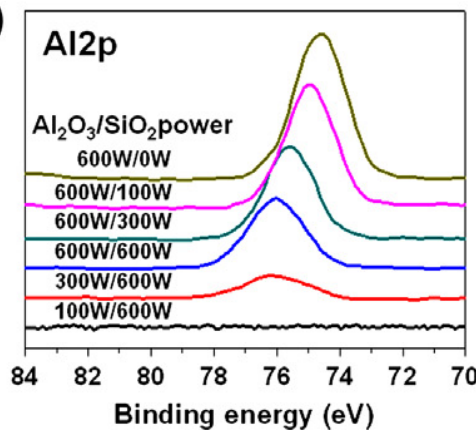

(b)

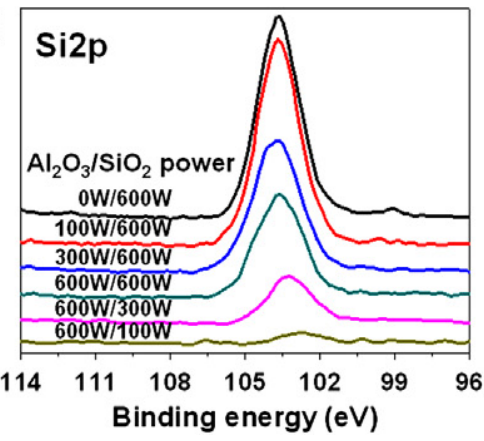

(c)

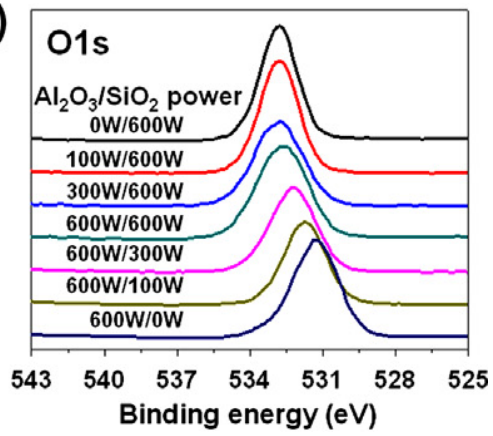

Fig. 3. Core level XPS spectra of (a) $\mathrm{Al} 2 \mathrm{p}$, (b) $\mathrm{Si} 2 \mathrm{p}$ and (c) $\mathrm{O}$ 1s in $\mathrm{Al}_{2} \mathrm{O}_{3} / \mathrm{SiO}_{2}$ mixture layers with differing power ratios. Compared with the binding energy peaks for the pure $\mathrm{Al}_{2} \mathrm{O}_{3}$ and $\mathrm{SiO}_{2}$ (i.e., at 600:0 W and 0:600 W data), the XPS spectra of the mixtures shows a shift in the peak with differing power ratio. Furthermore, when the power ratio was approximately 1:1, the peaks were broad.

Table 1

$\mathrm{Si} 2 \mathrm{p}, \mathrm{Al} 2 \mathrm{p}$ and $\mathrm{O} 1 \mathrm{~s}$ binding energies in differing $\mathrm{Al}_{2} \mathrm{O}_{3} / \mathrm{SiO}_{2}$ mixture films; the atomic percentages from the XPS quantitative analyses of different elements are indicated in square brackets, and FWHM values in parentheses.

\begin{tabular}{llll}
\hline $\mathrm{Al}_{2} \mathrm{O}_{3} / \mathrm{SiO}_{2}$ power ratio $(\mathrm{W}: W)$ & $\mathrm{Si} 2 \mathrm{p}(\mathrm{eV})(\mathrm{FWHM})[\mathrm{at} . \%]$ & $\mathrm{Al} 2 \mathrm{p}(\mathrm{eV})(\mathrm{FWHM})[\mathrm{at} . \%]$ & $\mathrm{O} 1 \mathrm{~s}(\mathrm{eV})(\mathrm{FWHM})[\mathrm{at} . \%]$ \\
\hline $0 / 600\left(\mathrm{SiO}_{2}\right)$ & $103.6(1.9)[35]$ & $* * *(* * *)[* * *$ & $532.7(1.8)[65]$ \\
$100 / 600$ & $103.6(1.9)[35]$ & $* * *(* *)[* * *$ & $532.7(1.8)[65]$ \\
$300 / 600$ & $103.6(2.1)[27]$ & $76.1(2.3)[7]$ & $532.6(2.3)[66]$ \\
$600 / 600$ & $103.6(2.2)[17]$ & $76.0(2.0)[17]$ & $532.5(2.4)[66]$ \\
$600 / 300$ & $103.2(2.1)[10]$ & $75.6(1.8)[24]$ & $532.2(2.2)[66]$ \\
$600 / 100$ & $102.7(2.1)[2]$ & $74.9(1.8)[33]$ & $531.7(2.2)[65]$ \\
$600 / 0\left(\mathrm{Al}_{2} \mathrm{O}_{3}\right)$ & $\mathrm{N} / \mathrm{A}$ & $74.6(1.9)[34]$ & $531.2(2.2)[66]$ \\
\hline
\end{tabular}

\subsection{Mechanical analysis of non-graded and graded films}

Fragmentation tests [28-31] were undertaken to verify the advantages of creating a graded architecture by examining the mechanical integrity of the layers, using a PES substrate. The elastic properties of the polymer (Young's modulus 2.5 GPa, Poisson's ratio 0.4) and of the $\mathrm{Al}_{2} \mathrm{O}_{3}$ and $\mathrm{SiO}_{2}$ layers were taken from the literature, and values for the composite layers were calculated using the rule of mixture. The cohesive and adhesive properties of the layers calculated from the fragmentation data are reported in Table 2, together with the elastic data.

\subsubsection{Cohesive properties of oxide layers}

Fig. 4 shows the early fragmentation stages of the layers investigated, plotting the density of tensile cracks $(C D)$ against the strain $\varepsilon$. The experimental data were fitted by the equation:

$C D(\varepsilon)=C D_{\text {sat }}\left(1-\exp \left\{-A\left(\varepsilon-\varepsilon_{1}\right)\right\}\right)$

where $C D_{\text {sat }}$ represents the $C D$ at saturation of the fragmentation process, $A$ is an adjustable factor which reflects the cracking rate (and is related to parameters such as the coating Weibull modulus) [30], and $\varepsilon_{1}$ is the COS. The COS was used to estimate the critical radius $\left(R_{\text {crit }}\right)$ at which cracks are initiated in the bending mode:

Table 2

Elastic, cohesive and adhesive properties of layers on PES.

\begin{tabular}{|c|c|c|c|c|c|c|c|c|c|c|c|}
\hline \multirow[t]{2}{*}{$\begin{array}{l}\text { Coating } \\
\text { composition }\end{array}$} & \multirow[t]{2}{*}{$\begin{array}{l}\text { Thickness } \\
h_{c}(\mathrm{~nm})\end{array}$} & \multicolumn{4}{|c|}{ Elastic properties } & \multicolumn{4}{|c|}{ Cohesive properties } & \multicolumn{2}{|c|}{$\begin{array}{l}\text { Adhesive } \\
\text { properties }\end{array}$} \\
\hline & & $\begin{array}{l}\text { Modulus } \\
E_{c}(\mathrm{GPa})\end{array}$ & $\begin{array}{l}\text { Poisson's } \\
\text { ratio }\left(v_{c}\right)\end{array}$ & $\begin{array}{l}\text { Dundurs } \\
\text { parameter } \\
(\alpha)\end{array}$ & $\begin{array}{l}\text { ERR } \\
\text { function } \\
(g)\end{array}$ & COS & $\begin{array}{l}\text { Critical } \\
\text { radius } \\
(\mathrm{mm})\end{array}$ & $\begin{array}{l}\text { Weibull } \\
\text { modulus } \\
(\mathrm{m})\end{array}$ & $\begin{array}{l}\text { Toughness } \\
G_{c}\left(\mathrm{~J} \mathrm{~m}^{-2}\right)\end{array}$ & $\begin{array}{l}C D_{\text {sat }} \\
\left(\mathrm{mm}^{-1}\right)\end{array}$ & $\begin{array}{l}\text { IFSS } \\
(\mathrm{MPa})\end{array}$ \\
\hline $\mathrm{Al}_{2} \mathrm{O}_{3}$ & 100 & 200 & 0.2 & 0.972 & 12.6 & 0.0056 & 17.7 & 3.50 & 12.1 & 135 & 45.0 \\
\hline $\mathrm{Al}_{2} \mathrm{O}_{3}$ & 140 & 200 & 0.2 & 0.972 & 12.6 & 0.0042 & 23.8 & 3.54 & 9.4 & - & - \\
\hline $\mathrm{Al}_{2} \mathrm{O}_{3}$ & 200 & 200 & 0.2 & 0.972 & 12.6 & 0.0038 & 26.3 & 2.42 & 11.0 & - & - \\
\hline $\begin{array}{l}\text { Mixed } \\
\mathrm{Al}_{2} \mathrm{O}_{3-}- \\
\mathrm{SiO}_{2}\end{array}$ & 100 & 140 & 0.2 & 0.960 & 10.3 & 0.0099 & 10.1 & - & 21.4 & - & - \\
\hline AGS & 140 & 140 & 0.2 & 0.960 & 10.3 & 0.0085 & 11.8 & - & 21.9 & - & - \\
\hline SGS & 140 & 140 & 0.2 & 0.960 & 10.3 & 0.0096 & 10.4 & 6.18 & 28.0 & 227 & 97.0 \\
\hline
\end{tabular}




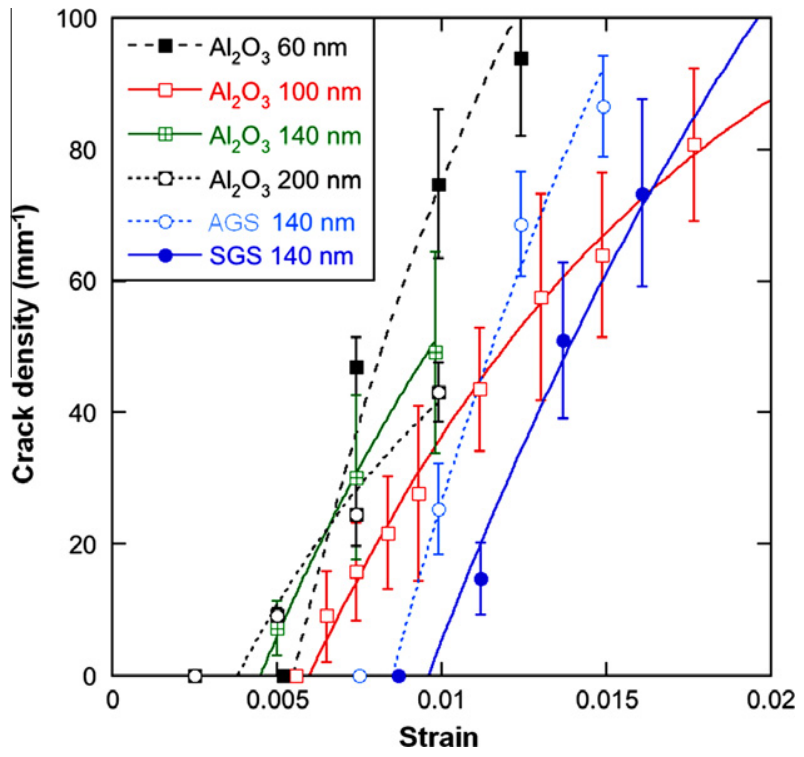

Fig. 4. Density of tensile cracks of inorganic oxide layers on a PES substrate vs. strain.

$R_{\text {crit }}=h_{t} /\left(2 \varepsilon_{1}\right)$

where $h_{t}=h_{s}+h_{c}$ is the total thickness of the coated substrate, and $h_{s}$ and $h_{c}$ are the thicknesses of the substrate and the coat layer, respectively.

The COS of the $\mathrm{Al}_{2} \mathrm{O}_{3}$ layers decreased from $0.56 \%$ to $0.38 \%$ as the coating thickness increased from $100 \mathrm{~nm}$ to $200 \mathrm{~nm}$. These COS values scale inversely with the square root of the layer thickness, as predicted by linear elastic fracture mechanics. The corresponding critical radius, calculated using Eq. (2), increased from $18 \mathrm{~mm}$ to $26 \mathrm{~mm}$. This means that the increasing thickness for an inorganic layer generates lower mechanical flexibility. The Weibull modulus of the layers, which characterizes their defect structure, was also derived from the early fragmentation stages using the approach set out in Ref. [30], and was found to be close to three for the alumina layers. The $\mathrm{COS}$ is determined by the energy released during the fracture event, which depends on the layer toughness, layer thickness and the layer/substrate elastic contrast. The toughness of the layers was calculated by assuming that it is equal to the energy release rate (ERR) at COS, using the approach detailed in Refs. [32,33]:

$G_{s s}=\frac{\pi}{2} \bar{E}_{c} \varepsilon_{1}^{2} g(\alpha, \beta)$

where $\bar{E}_{c}=E_{c} /\left(1-v_{c}^{2}\right)$ is the plane strain modulus of the layer $\left(E_{c}\right.$ and $v_{c}$ are the Young's modulus and Poisson's ratio of the layers), and $g(\alpha, \beta)$ is a function of the Dundurs parameters $\alpha$ and $\beta$, which describe the elastic mismatch of the layer/substrate system. For plane strain problems, $\alpha=\left(\bar{E}_{c}-\bar{E}_{s}\right) /\left(\bar{E}_{c}+\bar{E}_{s}\right)$, where $\bar{E}_{s}=E_{s} /\left(1-v_{s}^{2}\right)$ is the plane strain modulus of the substrate $\left(E_{s}\right.$ and $v_{s}$ are the Young's modulus and Poisson's ratio of the substrate). The ERR function $g$ depends mainly on the parameter $\alpha$; the present work used $\beta=\alpha / 4$ [32]. The Dundurs parame- ter $\alpha$ and the layer toughness are set out in Table 2. The toughness is close to $10 \mathrm{~J} \mathrm{~m}^{-2}$ for the $\mathrm{Al}_{2} \mathrm{O}_{3}$ layers.

The $\mathrm{COS}$ of a 100 -nm-thick $\mathrm{SiO}_{2}$ layer which was also deposited on the PES substrate was close to $1 \%$, corresponding to a critical radius of $10 \mathrm{~mm}$. The corresponding fracture toughness was $8.4 \mathrm{~J} \mathrm{~m}^{-2}$, which is slightly less than that of the $\mathrm{Al}_{2} \mathrm{O}_{3}$ layers. The improved $\mathrm{COS}$ and critical radius of the $\mathrm{SiO}_{2}$ layer over the $\mathrm{Al}_{2} \mathrm{O}_{3}$ are therefore due primarily to reduced elastic contrast $\left(g\left(\mathrm{SiO}_{2}\right)=7.1<\right.$ $\left.g\left(\mathrm{Al}_{2} \mathrm{O}_{3}\right)=12.6\right), \mathrm{SiO}_{2}$ being less stiff than $\mathrm{Al}_{2} \mathrm{O}_{3}$. To determine the effect of simple mixing (homogeneous composition without gradient), a layer of thickness $100 \mathrm{~nm}$ prepared by co-deposition at $600: 600 \mathrm{~W}$ of $\mathrm{Al}_{2} \mathrm{O}_{3}$ and $\mathrm{SiO}_{2}$ was tested. Mixing of these two components (i.e., simple mixtures) led to a COS similar to that of pure $\mathrm{SiO}_{2}$. Blending was therefore particularly effective in improving the mechanical resistance of the more brittle $\mathrm{Al}_{2} \mathrm{O}_{3}$ layer. Interestingly, the fracture toughness of this mixed composition was $21.4 \mathrm{~J} \mathrm{~m}^{-2}$, twice as high as that of the plain $\mathrm{Al}_{2} \mathrm{O}_{3}$ layers. This result is taken to be related to the nature of the bonding in the mixture. As shown by XPS measurements, the blend contained a certain amount of $\mathrm{Al}-\mathrm{O}-\mathrm{Si}$ bonding, whose valence and character (covalent or ionic) is different from each of the two pure materials $\left(\mathrm{SiO}_{2}\right.$ and $\left.\mathrm{Al}_{2} \mathrm{O}_{3}\right)$. Since the cohesive properties of a material are related to the nature of its chemical bonds, substitution of $\mathrm{Al}-\mathrm{O}-\mathrm{Al}$ bonds by $\mathrm{Al}-\mathrm{O}-\mathrm{Si}$ bonds is responsible for the improvement in toughness and hence of COS. A detailed and systematic analysis should be undertaken to confirm this statement, and in particular to clarify the role of possible influent parameters, such as the morphology for example.

The COS of the 140-nm-thick AGS and SGS layers was equal to $0.85 \%$ and $0.96 \%$, respectively (Fig. 4 and Table 2 ). The latter value is almost equal to that of the thinner $\mathrm{SiO}_{2}$ and $\mathrm{Al}_{2} \mathrm{O}_{3} / \mathrm{SiO}_{2}$ mixed layers. This was due to the toughness of the SGS, which was found to be the highest of all the materials investigated. The corresponding critical radius was close to $10 \mathrm{~mm}$. Moreover, the Weibull modulus of the SGS layer was twice as high as that of the $\mathrm{Al}_{2} \mathrm{O}_{3}$ layers, reflecting a narrower defect distribution in the SGS layer. It therefore appears that blending $\mathrm{Al}_{2} \mathrm{O}_{3}$ with $\mathrm{SiO}_{2}$ in a controlled and graded manner was the best way to increase the tensile properties of these inorganic layers. The superior mechanical properties of the sandwich graded architectures over alternative materials with similar composition (e.g., the mixed and AGS layers) is due primarily to their specific through-stiffness gradient, in addition to a probable residual stress gradient. Increasing the elastic modulus of the graded layers from the top surface to the core is known to improve the resistance to tensile stresses [34]. This is the case if the concentration gradient is smooth, without any steps or discontinuities, to avoid undue stress concentrations, as confirmed by AES. Furthermore, the presence of $\mathrm{Al}-\mathrm{O}-\mathrm{Si}$ shows an ideal transition from ionic to covalent bonding. Again, this architecture minimized the internal stresses in the film, with 
no stress concentration in particular areas of the film. Crack initiation at the surface was reduced further by the presence of higher compressive stresses in the superficial $\mathrm{SiO}_{2}$ compared with $\mathrm{Al}_{2} \mathrm{O}_{3}$.

\subsubsection{Adhesive properties of oxide layers}

Fig. 5 compares the fragmentation process of the 100nm-thick $\mathrm{Al}_{2} \mathrm{O}_{3}$ and the 140-nm-thick SGS layers, tested up to strain levels close to the saturation limit. Eq. (1) was used to fit the experimental data; the results are shown in Table 2. The interfacial shear strength (IFSS), which characterizes the adhesion between the inorganic layer and the PES substrate, was derived using the perfectly plastic Kelly-Tyson model [35]:

IFSS $=1.337 h_{c} \sigma_{\max }\left(l_{c}\right) C D_{\text {sat }}$

where $\sigma_{\max }\left(l_{c}\right)$ is the coating strength at saturation, and $l_{c}=1.496 / C D_{\text {sat }}$ is the critical stress transfer length $[28,30]$ :

$\sigma_{\max }\left(l_{c}\right)=\sigma_{0}\left(l_{c} / l_{0}\right)^{-1 / m} \Gamma(1+1 / m)$

Here $\sigma_{0}$ and $m$ denote the Weibull scale factor and modulus, respectively, and $l_{0}$ is a normalization length taken equal to $1 \mu \mathrm{m}$. The IFSS of the $\mathrm{Al}_{2} \mathrm{O}_{3}$ layer on the PES substrate was $45.0 \mathrm{MPa}$, which compares with the shear stress at yield $\tau_{Y}$ of the PES substrate estimated at $46 \mathrm{MPa}$ from the tensile strength of the polymer $\sigma_{Y}$, using the Von Mises criterion $\tau_{Y}=\sigma_{Y} / \sqrt{3}$. This reflects the good adhesion of the $\mathrm{Al}_{2} \mathrm{O}_{3}$ layer on PES, presumably due to the formation of covalent bonds between the two materials [36]. The IFSS of the SGS layer on the PES substrate was much higher, at 97.0 MPa. This value, considerably greater than the shear stress at yield $\tau_{Y}$ of the PES substrate, implies that the interface was able to strain harden. This again reflects the creation of chemical bonds during the deposition of the first $\mathrm{SiO}_{2}$ layer. Based on the cohesive and adhesive characterizations of inorganic films, the sandwich graded geome-

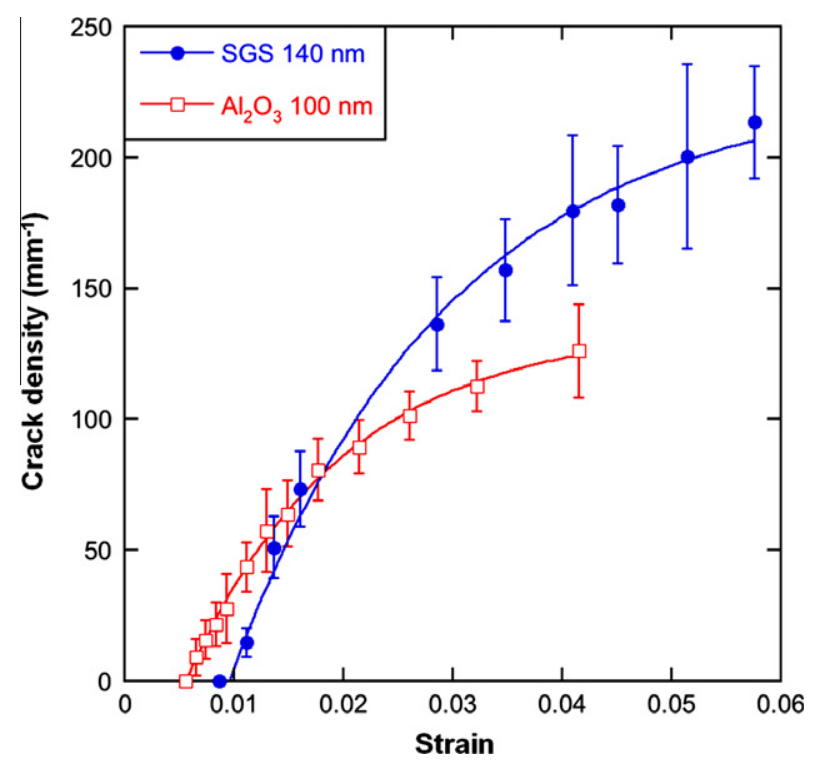

Fig. 5. Density of tensile cracks of $\mathrm{Al}_{2} \mathrm{O}_{3}$ and SGS layers on a PES substrate vs. strain. try, with an $\mathrm{Al}_{2} \mathrm{O}_{3}$ core layer surrounded by two $\mathrm{SiO}_{2}$-rich layers at the top and bottom of the film, gave the best performance based on both the cohesive and adhesive properties with the PES substrate.

\subsection{Optical properties}

It was checked whether films with compositionally graded structures preserved high optical transparency of the individual $\mathrm{Al}_{2} \mathrm{O}_{3}$ or $\mathrm{SiO}_{2}$ layers. The transmittance of the differing films with a total thickness of $100 \mathrm{~nm}$ on a $100-\mu \mathrm{m}$-thick PET film is shown in Fig. 6. Except for a slight decrease at wavelengths $>500 \mathrm{~nm}$, the optical transmittance of the graded samples remained similar to that of non-graded pure samples. The high transmittance of graded thin films is suitable for a variety of applications in optical electronic devices for which a high transparency is required, so as to minimize the loss of incident light passing through the films.

\subsection{Permeation characterizations}

The gas barrier properties of the films with their different layer architectures were examined for application to a thin film encapsulation of organic electronics. As a reference sample, the water permeation of single $\mathrm{Al}_{2} \mathrm{O}_{3}$ layers was first measured as a function of thickness; the results are shown in Fig. 7. The WVTR values decreased with increasing thickness, but reached a saturation value for a thickness just $<150 \mathrm{~nm}$. This result confirms that WVTR is not improved indefinitely with increasing thickness, because of the increase in the number of defects. A thickness of $140 \mathrm{~nm}$, corresponding to the best WVTR value for a pure $\mathrm{Al}_{2} \mathrm{O}_{3}$ single layer, was consequently chosen as reference, and the thickness of all other graded or mixed layers was set at that particular value.

The WVTR of the 140-nm-thick $\mathrm{SiO}_{2}$ layer was $25 \%$ higher (i.e., worse) than that of the reference $\mathrm{Al}_{2} \mathrm{O}_{3}$. In contrast, for the same thickness, the WVTR of the graded

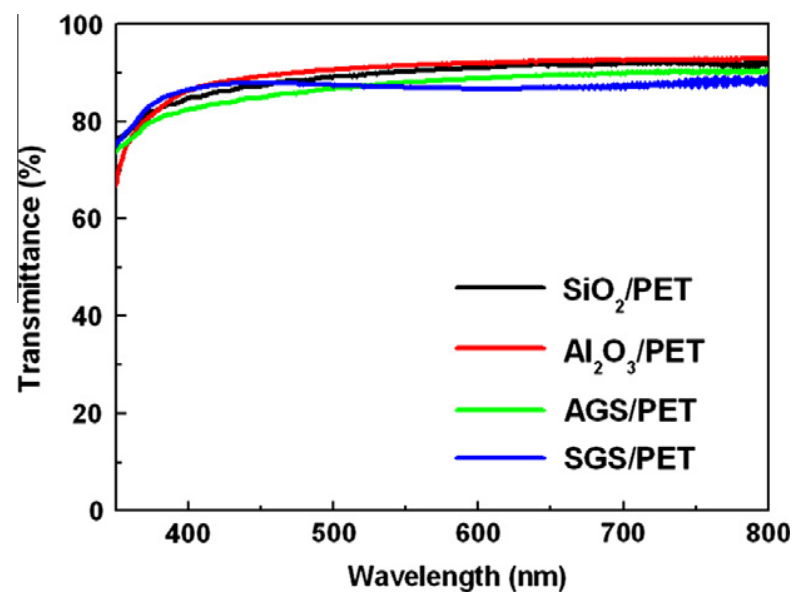

Fig. 6. Transmittance of pure $\mathrm{SiO}_{2}, \mathrm{Al}_{2} \mathrm{O}_{3}$, and graded structures on PET $(100 \mu \mathrm{m})$. The thickness of all inorganic single layers is $100 \mathrm{~nm}$. 


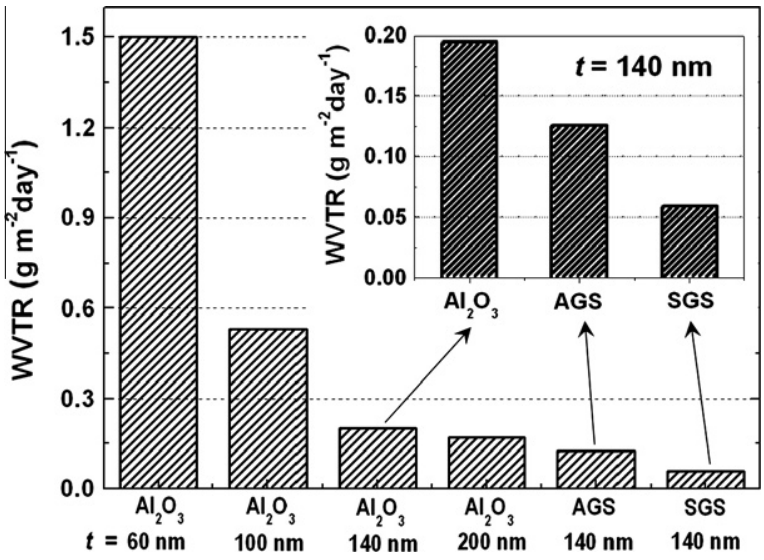

Fig. 7. Gas permeation property for pure $\mathrm{Al}_{2} \mathrm{O}_{3}$ with the different thicknesses $(60,100,140$, and $200 \mathrm{~nm})$ and graded structures $140 \mathrm{~nm}$ thick.

structures was improved by up to a factor of 3 (i.e., $0.059 \mathrm{~g} \mathrm{~m}^{-2} \mathrm{day}^{-1}$ for the sandwich graded layer) over the reference (see Fig. 7). The gas barrier properties follow a trend similar to that of the mechanical properties, with graded structures better than pure layers. The enhanced gas barrier performance is therefore attributed to the synergetic effect between better stress balance of the graded structure and the high local homogeneity of the film.

Also of interest is the effect of the Al-O-Si bonds in the graded film on its barrier properties. These bonds contribute to the enhanced mechanical properties, but it is unclear whether they are also directly responsible for the improvement in barrier properties. To settle this complicated question, an indirect method was used which measures the optical properties of the layer. It was found that the refractive index of the mixed films (i.e., non-graded structure) can be used to estimate the gas barrier behavior, since the optical properties depend on the polarizability of the oxides and the packing density of the films [37]. In other words, the refractive index increases when the polarizability and the density of the barrier layer increase, resulting in a better gas barrier. The refractive index of inorganic layers made up of a homogeneous mixture of $\mathrm{Al}_{2} \mathrm{O}_{3}$ and $\mathrm{SiO}_{2}$ was measured as a function of the atomic concentra- tion of $\mathrm{Al}_{2} \mathrm{O}_{3}$, from $0 \%$ to $100 \%$, and a linear increase was observed (Fig. 8a). These results reflect the superior barrier properties of $\mathrm{Al}_{2} \mathrm{O}_{3}$ over $\mathrm{SiO}_{2}$, but the linear increase indicates that the $\mathrm{Al}-\mathrm{O}-\mathrm{Si}$ bonds did not contribute directly to the barrier properties. Fig. $8 \mathrm{~b}$ confirms that the barrier properties of the $\mathrm{Al}_{2} \mathrm{O}_{3} / \mathrm{SiO}_{2}$ mixtures, without any gradient, lay between those of the two pure materials. These results confirm the superiority of using a graded architecture for improving the barrier properties, rather than a homogeneous mixture of two components, given the same average composition. Consequently, even if the mechanical properties of the homogeneous mixture were significantly improved over pure $\mathrm{Al}_{2} \mathrm{O}_{3}$, the mixture did not maintain the excellent barrier properties of pure $\mathrm{Al}_{2} \mathrm{O}_{3}$ layers. In contrast, the graded sandwich architecture with a pure $\mathrm{Al}_{2} \mathrm{O}_{3}$ zone preserved in the core of the film combined superior mechanical performance with enhancing the barrier properties. The progressive concentration change to $\mathrm{SiO}_{2}$ at the top and the bottom part of the layer preserved the overall mechanical properties of the layer, and protected the $\mathrm{Al}_{2} \mathrm{O}_{3}$-rich zone from damage.

\section{Conclusions}

The graded approach used in this study for the deposition of inorganic layers demonstrated clear potential for the fabrication of inorganic oxide thin films with superior mechanical stability (i.e., enhanced toughness) and without losing optical transparency. Through the power control of the co-sputtering unit, the structural design of the thin film could easily be tailored on the nanometer scale. The absence of interfaces and the alternating bonding structures between different materials allowed the production of thin films with a chemical composition that was finely adjusted throughout the thickness. Furthermore, the internal chemical and mechanical balancing across the thickness could provide improved mechanical properties of inorganic thin films. Materials, blending ratios and architectures different from those used in the present study should give rise to further improvement in the mechanical and barrier performance of single inorganic layers. This approach makes
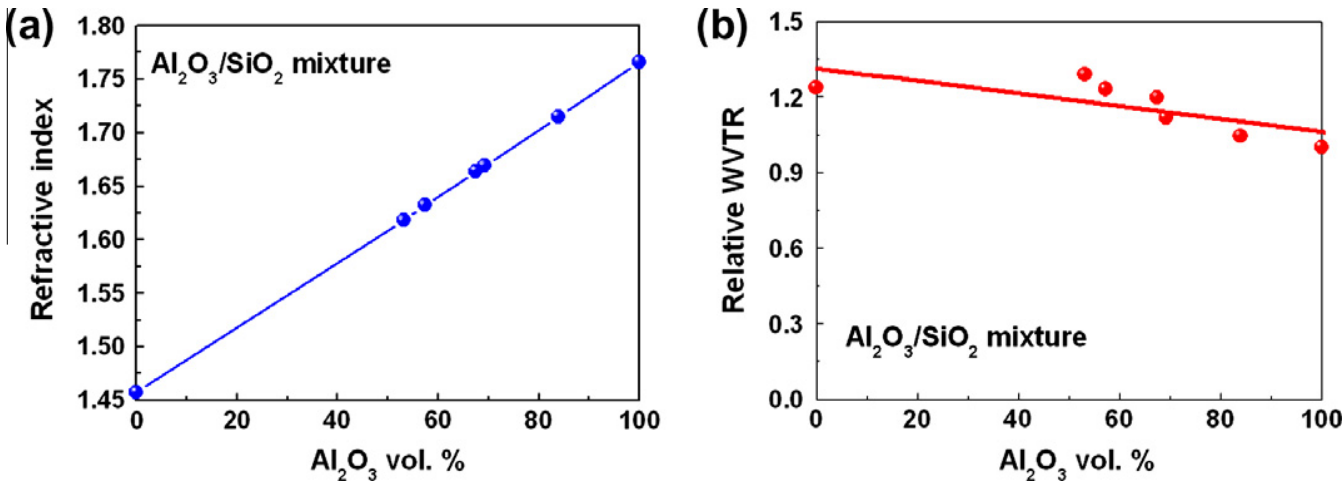

Fig. 8. Relationship between optical and permeation properties: (a) refractive index of simple mixtures of $\mathrm{Al}_{2} \mathrm{O}_{3}$ and $\mathrm{SiO}_{2}$, where $0 \%$ in the $x$-axis denotes pure $\mathrm{SiO}_{2}$ and (b) relative WVTR for the mixtures used in (a). 
it possible to choose the material composition at critical points of the inorganic thin film so as to optimize performance. Critical points include the composition at the interface with the polymer substrate, to improve interfacial adhesion; the composition at the top surface to avoid crack initiation or control the density of defects at the surface; and the composition in the core, to give better balance of stresses within the film.

\section{Acknowledgement}

This work was supported financially by Samsung Advanced Institute of Technology.

\section{References}

[1] Mann S, Ozin GA. Nature 1996;382:313.

[2] Li J, Han Y. Langmuir 2006;22:1885.

[3] Deepa M, Srivastava AK, Lauterbach S, Govind, Shivaprasad SM, Sood KN. Acta Mater 2007;55:6095.

[4] Kim DW, Lee DY, Lee HS, Lee WH, Kim YH, Han JI, et al. Adv Mater 2007;19:678.

[5] Liu F, Li X, Zhao Q, Hou Y, Quan X, Chen G. Acta Mater 2009;57:2684.

[6] Placencia D, Wang W, Shallcross RC, Nebesny KW, Brumbach M, Armstrong NR. Adv Funct Mater 2009;19:1913.

[7] Lee YG, Choi Y-H, Kee IS, Shim HS, Jin Y, Lee S, et al. Org Electron 2009;10:1352.

[8] Choi Y-H, Lee YG, Lee K-H, Bulliard X, Lee S, Choi D, et al. Scripta Mater 2010;62:447.

[9] Choi Y, Choi D, Lee LP. Adv Mater 2010;22:1754.

[10] Choi D, Choi Y, Hong S, Kang T, Lee LP. Small 2010;6:1741.

[11] Lu N, Suo Z, Vlassak JJ. Acta Mater 2010;58:1679.

[12] Choi M-Y, Choi D, Jin M-J, Kim IS, Kim S-Y, Choi J-Y, et al. Adv Mater 2009;21:2185.

[13] Choi D, Choi M-Y, Shin HJ, Yoon SM, Seo JS, Lee S, et al. J Phys Chem C 2010;114:1379.
[14] Kim T-H, Choi WM, Kim D-H, Meitl MA, Menard E, Jiang H, et al. Adv Mater 2008;20:2171.

[15] Henry BM, Erlat AG, McGuigan A, Grovenor CRM, Briggs GAD, Tsukahara Y, et al. Thin Solid Films 2001;382:194.

[16] Mandlik P, Gartside J, Han L, Cheng I-C, Wagner S, Silvernail JA, et al. Appl Phys Lett 2008;92:103309.

[17] Carcia PF, McLean RS, Reilly MH, Groner MD, George SM. Appl Phys Lett 2006;89:031915.

[18] Muller DA, Nakagawa N, Ohtomo A, Grazul JL, Hwang HY. Nature 2004;430:657.

[19] Kwak S, Jun J, Jung E-S. Langmuir 2009;25:8051.

[20] Mattsson J, Forrest JA, Borjesson L. Phys Rev E 2000;62:5187.

[21] Nardin C, Winterhalter M, Meier W. Langmuir 2000;16:7708.

[22] Mallwitz F, Goedel WA. Angew Chem Int Ed 2001;40:2645.

[23] Jitcharoen J, Padture NP, Giannakopoulos AE, Suresh S. J Am Ceram Soc 1998;81:2301.

[24] Yin HM, Sun LZ, Paulino GH. Acta Mater 2004;52:3535.

[25] Cannillo V, Montorsi M, Siligardi C, Sola A, Portu Gd, Micele L, et al. J Eur Ceram Soc 2006;26:1411.

[26] Frank FC, Lawn BR. Proc R Soc London A 1967;299:291.

[27] Leterrier Y, Médico L, Demarco F, Månson J-AE, Escola-Figuera M, Kharrazi-Olsson M, et al. Thin Solid Films 2004;460:156.

[28] Leterrier Y, Fischer C, Médico L, Demarco F, Månson J-AE, Bouten P, DeGoede J, Nairn JA. In: 46th Annual technical conference proceedings of the society of vacuum coaters; 2003, vol. 505. p. 856.

[29] Bieder A, Gondoin V, Leterrier Y, Tornare G, PRv Rohr, Månson JAE. Thin Solid Films 2007;515:5430.

[30] Leterrier Y, Boogh L, Andersons J, Månson J-AE. J Polym Sci Part B 1997;35:1449.

[31] Leterrier Y, Andersons J, Pitton Y, Månson J-AE. J Polym Sci Part B 1997;35:1463.

[32] Beuth JL. Int J Sol Struct 1992;29:1657.

[33] Andersons J, Modniks J, Leterrier Y, Tornare G, Dumont P, Månson J-AE. Theor Appl Fract Mech 2008;49:151.

[34] Schwarzer N. Surf Coat Technol 2000;133/134:397.

[35] Kelly A, Tyson WR. J Mech Phys Sol 1965;13:329.

[36] Howells DG, Henry BM, Leterrier Y, Månson J-AE, Madocks J, Assender HE. Surf Coat Tech 2008;202:3529.

[37] Koo WH, Jeong SM, Choi SH, Baik HK, Lee SM, Lee SJ. J Phys Chem B 2004;108:18884. 